\title{
Giant Fecaloma Causing Large Bowel Obstruction: A Case Report
}

\author{
Arcelia Guerson Gil*, Qiang Liu and Sammy Ho
}

Internal Medicine, Jacobi Medical Center/Albert Einstein College of Medicine, USA

\section{ISSN: 2637-7632}

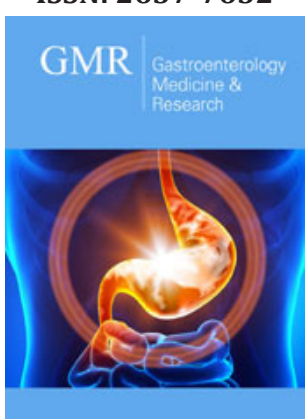

*Corresponding author: Arcelia Guerson Gil, MD, Internal Medicine, Jacobi Medical Center/Albert Einstein College of Medicine, USA

Submission: 海 July 20, 2020

Published: 佣August 10, 2020

Volume 5 - Issue 1

How to cite this article: Arcelia Guerson Gil, Qiang Liu and Sammy Ho. EUS-Guided Micro-Forceps Biopsy for the Diagnosis of Lymphoma: A Case Series. Gastro Med Res. 5(1). GMR.000602. 2020.

DOI: $10.31031 /$ GMR.2020.05.000602

Copyright@ Arcelia Guerson Gil, This article is distributed under the terms of the Creative Commons Attribution 4.0 International License, which permits unrestricted use and redistribution provided that the original author and source are credited.

\begin{abstract}
Fecalomas are masses of hardened stool that are typically impacted in the sigmoid colon and rectum. Fecalomas are commonly associated with chronic constipation, Hirschsprung's disease, Chagas disease, and multiple psychiatric conditions. We present a case of a giant fecaloma resulting in complete large bowel obstruction and suggest a five-year abdominal ultrasound monitoring of adults presenting with chronic constipation and/or chronic nonspecific gastrointestinal (GI) complaints.
\end{abstract}

\section{Introduction}

Fecaloma is an accumulation of hardened impacted stool typically located in the sigmoid colon and rectum [1-3]. The accumulation of fecal matter builds up in the intestine and stagnates, further increasing in size and volume taking on the characteristics of a tumour $[4,5]$. Symptoms of a fecaloma are commonly nonspecific including chronic constipation, vague abdominal pain after meals, and weight loss [6]. In cases of large fecaloma, patients may feel a palpable hardened mass in their abdomen. Fecalomas have been associated with elderly patients with chronic constipation, psychiatric conditions, Hirschsprung's disease, and Chagas disease [7]. Fecaloma is diagnosed radiologically through x-rays, barium enema, abdominal ultrasound, or abdominal computed tomography (CT) scans [8]. Most cases are managed conservatively with laxatives and enemas. However, some cases are refractory to conservative management [9], as in this case, requiring surgical intervention for removal of the fecaloma preventing further complications. We report a case of a giant fecaloma causing a complete large bowel obstruction requiring surgical management.

\section{Case Report}

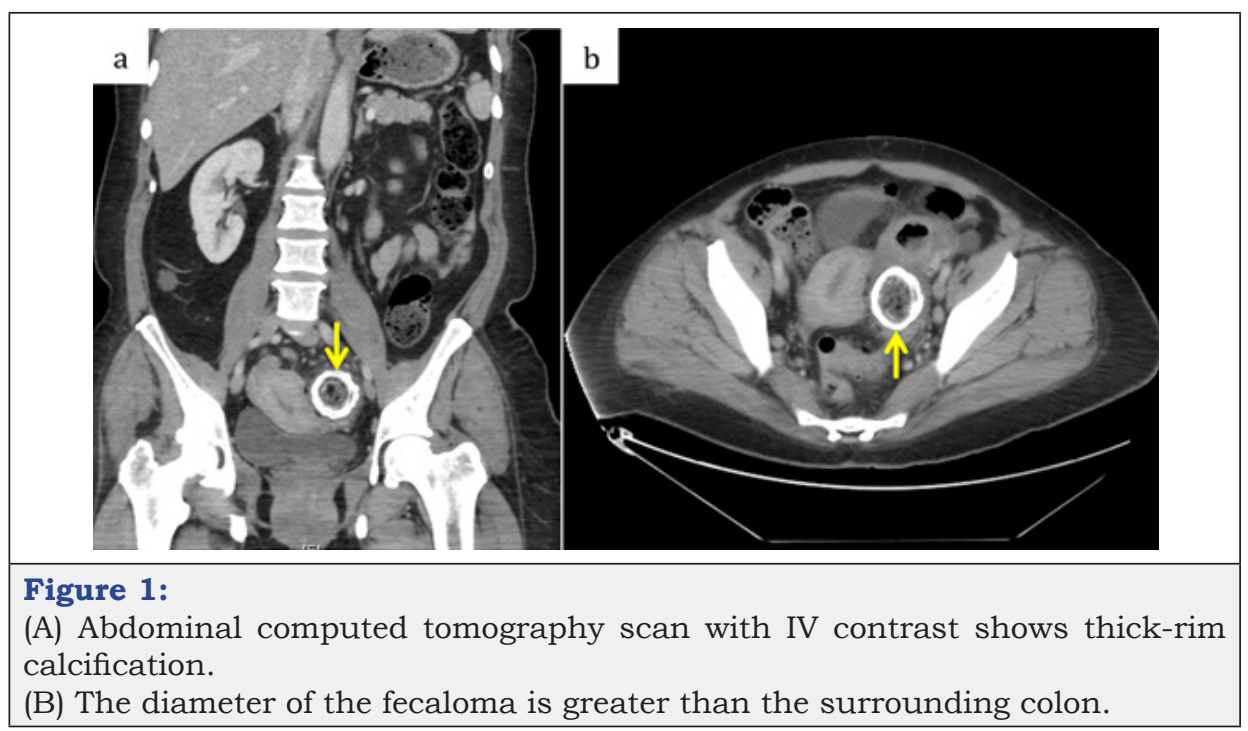


A 46-year-old-female with a history of chronic constipation and abdominoplasty (10+ years ago) presented with a one-month history of worsening abdominal pain, nausea, and vomiting. The patient denied the passage of flatus and stool three days prior to presentation. On physical examination, the patient appeared well with normal vital signs. Abdominal examination was remarkable for distention in the periumbilical area, hypoactive bowel sounds, and diffuse tenderness across the whole abdomen. Hematologic testing, basic metabolic panel, and liver biochemical tests were normal. An abdominal CT scan with intravenous (IV) contrast revealed a densely calcified rim of a fecaloma measuring $4.7 \mathrm{~cm}$ in diameter located in the mid sigmoid colon with wall thickening around the mass (Figure 1). The sigmoid collapse was noted at the level of the fecaloma with no fluid collections. At the time of admission, there was a mild bowel obstruction noted. The following day, the patient developed worsening abdominal pain. A two-view x-ray of the abdomen revealed air distended large and small bowel loops indicating complete large bowel obstruction (Figure 2). As a result, the patient underwent an emergency exploratory laparotomy that resulted in partial colon resection with colostomy formation. A giant fecaloma and a small piece of old gauze found in the patient's rectum was retrieved. Post-operative period of the patient was uneventful. The ostomy was deemed a candidate for reversal four months after the exploratory laparotomy.

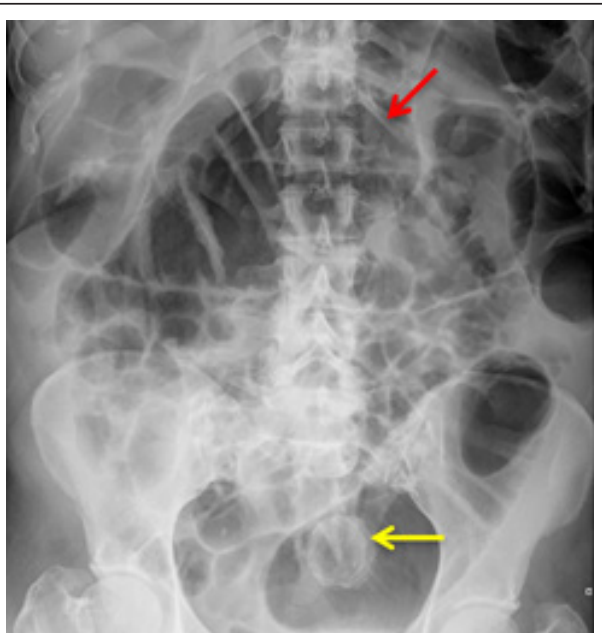

Figure 2: Abdominal X-ray shows fecaloma (yellow arrow) and air distended intestines (red arrow) secondary to complete large bowel obstruction.

\section{Discussion}

Fecaloma is a result of the hardening of feces into lumps of many different sizes that are typically denser than fecal matter in cases of fecal impaction [6]. The most common location of a fecaloma is the distal sigmoid colon. The mass is typically composed of intestinal debris and fecal matter; however, foreign bodies, such as seen in this case, can serve as a nidus for formation [6]. Fecaloma presents variably from urinary retention [10] to toxic megacolon $[1,5,11]$. Diagnostic confirmation is made through an abdominal CT scan with IV contrast that shows a fecal mass that is greater than or equal to the diameter of the colon or through colonoscopy [12]. Complications seen in patients with fecaloma include hydronephrosis, nerve compression resulting in sciatica, deep vein thrombosis (DVT), ulceration, bleeding, obstruction, and colon perforation at the site of the fecaloma [6]. Most of the fecal impactions are successfully managed conservatively with bowel rest, laxative, enema, and digital evacuation [13]. As a result, the consulting gastroenterology team in this case had initially recommended a conservative regimen of tap water enemas and polyethylene glycol (PEG) for three days prior to intended colonoscopy with the use of diet coca-cola to aid in dissolving and breaking up the calcified mass. Although this represents an innovative approach to conservative management some have argued against it. Tchanagi et al suggests that surgery should be considered first-line in the treatment of giant fecaloma [14]. In the report, the authors argued that the peritoneal complications of rupture and bowel resection in cases of emergency exploratory laparoscopies for giant fecaloma outweighed the benefits of firstline conservative management.

The impressive rim calcification of the mass as seen on the abdominal CT, indicated that the large fecaloma was present in the patient for many years (Figure 1). The patient's description of her bowel habits was significant for chronic constipation as well as chronic vomiting, likely secondary to fluid accumulation proximal to the fecaloma. Unfortunately, the fecaloma was not identified until this hospitalization. This case demonstrates the need for improved diagnostic workup of nonspecific GI complaints and chronic constipation. As fecaloma is a radiological diagnosis, this report suggests that adults with chronic constipation and chronic nonspecific GI symptoms be screened for fecaloma by routine abdominal ultrasound every five years. Additionally, positive or indeterminate ultrasound results should be followed by an abdominal x-ray. Early suspicion and intervention are required to achieve favourable outcomes in patients with giant fecalomas. This report considers the risks of complications by fecaloma to outweigh the risks and potential harm of abdominal ultrasound or abdominal x-ray in adults with chronic constipation and nonspecific GI complaints. Furthermore, it should be noted that the importance of early surgical intervention should be heavily considered over conservative management, as in the present case.

\section{References}

1. Rajagopal A, Martin J (2002) Giant fecaloma with idiopathic sigmoid megacolon: Report of a case and review of the literature. Dis Colon Rectum 45(6): 833-835.

2. Zimmers T (1984) Giant calcified fecaloma. Ann Emerg Med 13(9 Pt 1): 749 .

3. Campbell JB, Robinson AE (1973) Hirschsprung's disease presenting as calcified fecaloma. Pediatr Radiol 1(3): 161-163.

4. Yucel AF, Akdogan RA, Gucer H (2012) A giant abdominal mass: Fecaloma. Clin Gastroenterol Hepatol 10(2): e9-e10.

5. Zurabishvili K, Rekhviashvili A, Sakhamberidze M, Tsiklauri K (2015) A case of giant fecaloma in a 24-year-old woman. Georgian Med News 240: $11-14$

6. Garisto JD, Campillo L, Edwards E, Harbour M, Ermocilla R (2009) Giant fecaloma in a 12-year-old-boy: A case report. Cases J 2(1): 127. 
7. Caiazzo P, De Martino C, Del Vecchio G, Di Lascio P, Marasco M, et al. (2013) Megacolon for a giant faecaloma with unlucky outcome: case report and review of the literature. Ann Ital Chir 84(3): 319-322.

8. Cid AA, Pietruk T, Bidari CZ, Ehrinpreis MN (1981) Cecal fecaloma mimicking colonic neoplasm. Dig Dis Sci 26(12): 1134-1137.

9. Rajagopal A, Martin J (2002) Giant fecaloma with idiopathic sigmoid megacolon: Report of a case and review of the literature. Dis Colon Rectum 45(6): 833-835.

10. Park JS, Park TJ, Hwa JS, Seo JH, Park CH, et al. (2013) Acute urinary retention in a 47-month-old girl caused by the giant fecaloma. Pediatr Gastroenterol Hepatol Nutr 16(3): 200-205.

11. Ribas Y, Bargallo J, Lamas S, Aguilar F (2013) Idiopathic sigmoid megacolon with fecal impaction and giant calcified fecaloma. Am Surg 79(2): E96-E97.
12. Altomare DF, Rinaldi M, Sallustio PL (2009) Giant fecaloma in an adult with severe anal stricture caused by anal imperforation treated by proctocolectomy and ileostomy: Report of a case. Dis Colon Rectum 52(3): 534-537.

13. Kim KH, Kim YS, Seo GS, Choi CS, Choi SC (2007) A case of fecaloma resulting in the rectosigmoid megacolon. Kor J Neurogastroenterology and Motility 13(1): 81-85.

14. Tchangai B, Alassani F, Tchaou M, Attipou K (2016) Staged surgery for giant fecaloma complicating idiopathic megacolon. Open Journal of Gastroenterology 6(12): 418-422.

For possible submissions Click below: 